\title{
Macropinocytosis: New Insights Into Its Underappreciated Role in Innate Immune Cell Surveillance
}

\author{
Johnathan Canton* \\ Immunobiology Laboratory, The Francis Crick Institute, London, United Kingdom
}

Macropinocytosis has received increasing attention in recent years for its various roles in nutrient acquisition, immune surveillance, and virus and cancer pathologies. In most cases macropinocytosis is initiated by the sudden increase in an external stimulus such as a growth factor. This "induced" form of macropinocytosis has been the subject of much of the work addressing its mechanism and function over the years. An alternative, "constitutive" form of macropinocytosis restricted to primary innate immune cells also exists, although its mechanism has remained severely understudied. This mini-review focuses on the very recent advances that have shed new light on the initiation, formation

OPEN ACCESS

Edited by:

Uday Kishore,

Brunel University London,

United Kingdom

Reviewed by:

Kushagra Bansal,

Harvard Medical School,

United States

Gudrun Stenbeck,

Brunel University London,

United Kingdom

*Correspondence:

Johnathan Canton

johnathancanton@gmail.com

Specialty section:

This article was submitted to

Molecular Innate Immunity,

a section of the journal

Frontiers in Immunology

Received: 11 June 2018 Accepted: 14 September 2018

Published: 02 October 2018

Citation:

Canton J (2018) Macropinocytosis: New Insights Into Its

Underappreciated Role in Innate Immune Cell Surveillance.

Front. Immunol. 9:2286.

doi: 10.3389/fimmu.2018.02286 and functional relevance of constitutive macropinocytosis in primary innate immune cells. An emphasis is placed on how this new understanding of constitutive macropinocytosis is helping to define the sentinel function of innate immune cells including polarized macrophages and dendritic cells.

Keywords: macropinocytosis, macropinosome, PRRs, pattern recognition receptors (PRRs), antigen presentation, macrophages, dendritic cells, Nod2 signaling adaptor protein

\section{INTRODUCTION}

The ability of eukaryotic cells to internalize extracellular material was first recognized at the turn of the nineteenth century by Ilya Metchnikoff (1). Metchnikoff documented the internalization of large particulate structures by amoeboid cells in starfish larva and referred to the process as phagocytosis, or "cell eating." Almost half a century later, in 1931, Warren H. Lewis observed the uptake of extracellular fluid by cells in vitro and coined the term pinocytosis, or "cell drinking" (2). In the time since it was first observed, pinocytosis has been recognized to represent a broad array of cellular internalization, or endocytic, pathways including clathrin-mediated endocytosis, caveolae-dependent uptake and the CLIC/GEEC pathway. These pathways represent entire fields of study and continue to be actively investigated. One pinocytic pathway, however, has received far less attention-macropinocytosis.

Macropinocytosis is initiated by the actin-driven extension of plasma membrane ruffles. Occasionally, membrane ruffles form a cup-like structure or nascent macropinosome that seals at its distal tips to form a relatively large $(>250 \mathrm{~nm})$, phase-bright endosome termed a macropinosome. Subsequent membrane fusion and fission interactions with various organelles, primarily components of the endocytic pathway, result in the formation of a mature, acidic, and often tubular structure termed a macropino-lysosome. This series of events has been welldocumented for growth factor-induced macropinocytosis in non-myeloid cell types and has been reviewed extensively elsewhere (3-5). Somewhat surprisingly though, it has been tacitly assumed that these mechanistic insights transfer to cells of the innate immune system. 
More recently, the constitutive form of macropinocytosis in innate immune cells, specifically human monocyte-derived macrophages (hMDMs) and human monocyte-derived dendritic cells (hMDCs), has in fact been found to be mechanistically different. Constitutive macropinocytosis, for example, requires the presence of extracellular calcium, is less sensitive to perturbations in intracellular/cytosolic $\mathrm{pH}$ and forms morphologically distinct macropinosomes [for a detailed comparison of growth-factor induced and constitutive macropinocytosis, please see reference (6)]. Moreover, constitutive macropinocytosis appears to be restricted to primary innate immune cells, most often immature dendritic cells and macrophages, and has been observed in these cell types both in vitro and in vivo (7-9). The rate at which constitutive macropinocytosis occurs is staggering. Indeed, in their pioneering work, Steinman et al. observed macrophages internalizing their entire cell surface every $33 \mathrm{~min}$ (10). Given the significant energy cost of undergoing such an astoundingly active mode of endocytosis, the evolutionary conservation of constitutive macropinocytosis attests to its functional significance. Nevertheless, it remains severely understudied in dendritic cells and even more so in macrophages.

The lack of understanding of constitutive macropinocytosis in primary innate immune cells is largely a result of the notorious difficulty in both the culture and genetic manipulation of primary immune cells. Fortunately, recent advances in our understanding of innate immune cell ontogeny and culture as well as improved systems for the genetic manipulation of primary cells, such as the CRISPR technology, have allowed for a renewal of interest in this phenomenon. This mini-review will place its focus on the constitutive form of macropinocytosis in primary polarized macrophages and dendritic cells. Recent revelations in the initiation, mechanism, and functional relevance will be discussed. Trends in the field will be highlighted and a new perspective on how constitutive macropinocytosis is essential to the functioning of macrophages and dendritic cells in homeostasis, immune surveillance and the initiation of an adaptive immune response will be proposed.

\section{THE MECHANICS OF CONSTITUTIVE MACROPINOCYTOSIS}

Innate immune cells, like macrophages and immature dendritic cells, continuously elaborate dynamic membrane protrusions in a process referred to as membrane ruffling. This process is essential to both the housekeeping and immune functioning of these cells as it facilitates the capture of phagocytic targets thereby dramatically improving the efficiency with which they clear both potential pathogens and metabolic debris (11). Membrane ruffling is also the first step to forming a macropinosome (Figure 1) (12). This can be initiated by the sudden increase in concentration of an inducing stimulus such as a growth factor or microbe associated molecular pattern (MAMP) (8, 12). This induced form of macropinocytosis is not unique to macrophages and dendritic cells and has been reviewed elsewhere $(5,13)$. However, the constitutive ruffles mentioned above also occasionally seal at their distal tips to form macropinosomes. This constitutive form of macropinocytosis is unique to innate immune cells, with the notable exception of oncogene-transformed malignant cells (14).

The question of whether or not the constitutive ruffling of phagocytes was initiated and maintained by an ever present external stimulus or was the result of a cell intrinsic constitutively active driver of membrane protrusions had remained a mystery until very recently. In a study comparing growth factor induced and constitutive macropinocytosis in primary human monocytederived macrophages and primary human monocyte-derived dendritic cells, it was shown that extracellular calcium is the driver of constitutive macropinocytosis $(6,9)$. Extracellular calcium is sensed through the $G$ protein-coupled receptor (GPCR) calcium sensing receptor (CaSR), which upon ligation results in the transient generation of key lipid mediators on the cytosolic leaflet of the plasma membrane-notably phosphatidic acid (PtdOH) and phosphatidylinositol 3,4,5trisphosphate $\left[\operatorname{PtdIns}(3,4,5) \mathrm{P}_{3}\right] . \mathrm{PtdOH}$ and $\operatorname{PtdIns}(3,4,5) \mathrm{P}_{3}$ coordinate the recruitment and activation of actin nucleators at the plasma membrane in several converging steps. Firstly, several guanine nucleotide exchange factors (GEFs), such as DOCK2 and TIAM1 $(15,16)$, harbor polybasic domains that are electrostatically attracted to the negatively charged head groups of the phosphoinositide intermediates generated at the plasma membrane. GEFs in turn activate small GTPases, such as $\operatorname{Rac} 1 / 2$, that drive actin polymerization via the activation of downstream actin nucleation promoting complexes, such as the SCAR/WAVE complex and WASp (17-19). Another lipid mediator, phosphatidylinositol 4,5-bisphosphate [PtdIns $(4,5) \mathrm{P}_{2}$ ] is also transiently generated at sites of ruffle formation through the recruitment of type I phosphatidylinositol phosphate kinase by $\operatorname{PtdOH}(15,20,21)$. PtdIns $(4,5) \mathrm{P}_{2}$ can be further converted into either PtdIns $(3,4,5) \mathrm{P}_{3}$ through the action of phosphatidylinositol 3-kinase or hydrolyzed into diacylglycerol (DAG) and inositol 3,4,5-trisphosphate $\left(\mathrm{IP}_{3}\right)$ by phospholipases $(12,22,23)$. DAG is then converted into PtdOH by diacylglycerol kinase (DGK) thereby bolstering the aforementioned activation of actin nucleation promoting complexes. Ultimately, these events result in the formation of an Arp2/3-dependent branched actin network at the plasma membrane driving dynamic protrusions from the dorsal surface of the cell (Figure 1). Importantly, in the absence of extracellular calcium neither PtdIns $(3,4,5) \mathrm{P}_{3}$ nor $\mathrm{PtdOH}$ is generated at the plasma membrane in phagocytes outlining the importance of this signal in the maintenance of constitutive ruffle formation (6).

A membrane ruffle, however, is not a macropinosome. Only a small fraction of the membrane ruffles generated by phagocytes seal to become macropinosomes. Whether or not there are specialized ruffles that are destined to become macropinosomes has been the subject of speculation for quite some time. Joel Swanson and colleagues have shown that in addition to the numerous linear protrusions from the plasma membrane, specialized circular ruffles enriched in PtdIns $(3,4,5) \mathrm{P}_{3}$ were likely to seal into macropinsomes (23), but the form of macropinocytosis being studied was growth factor induced and not constitutive macropinocytosis. This is 


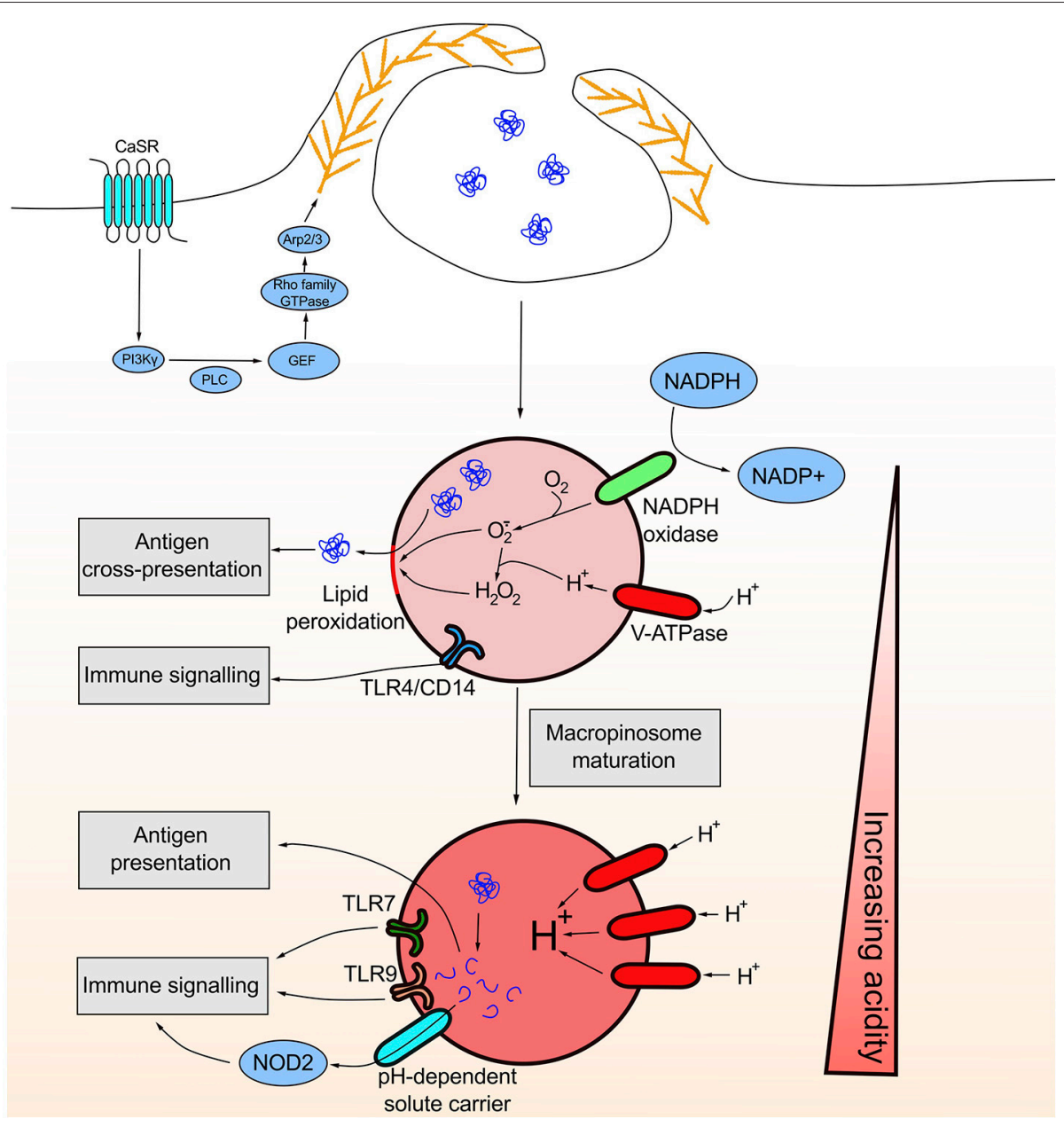

FIGURE 1 | Constitutive macropinocytosis is initiated by the sensing of extracellular calcium by the G protein-coupled receptor CaSR. CaSR ligation initiates a signaling cascade ultimately resulting in the elaboration of an Arp2/3 dependent branched actin network at the plasma membrane that drives constitutive ruffling. Early macropinosomes are less acidic due to limited contact with late endosomes/lysosomes and likely NADPH oxidase activity. The generation of reactive oxygen species damages the integrity of the macropinosome membrane through lipid peroxidation thus allowing for the release of antigen into the cytosol necessary for subsequent cross-presentation. As the macropinosome matures, the lumen becomes increasingly acidic allowing for the activation of protease and lipases with acidic $\mathrm{pH}$ optima. This degradative environment facilitates the generation of peptides that can bind MHCIl for presentation. Similarly, the degradative environment can liberate NOD1/2 ligands that can be transported in a pH-dependent manner across the macropinosomal membrane into the cytosol where they can bind cytosolic PRRs. Luminal ligands for membrane bound PRRs such as TLR4, TLR7 and TLR9 can also bind their respective receptors once internalized.

also complicated by the observation that in primary human macrophages and dendritic cells, which ruffle constitutively, PtdIns $(3,4,5) \mathrm{P}_{3}$ appears to be enriched in numerous ruffles at the plasma membrane, some of which do not seal to form macropinosomes $(6,9)$. Moreover, it was recently shown that the sequential hydrolysis of $\operatorname{PtdIns}(3,4,5) \mathrm{P}_{3}$ into phosphatidylinositol 3,4-bisphosphate and ultimately into phosphatidylinositol 3-phosphate is required for the closure of ruffles into macropinosomes (22), but exactly how that promotes closure is still unknown. However, new techniques allowing for greater spatial and temporal resolution of individual ruffles, such as lattice light sheet microscopy, are now being applied to the study of macropinocytosis in Dictyostelium (24) and could potentially allow for the visualization of individual nascent macropinosomes in mammalian phagocytes. Indeed, there is much to be learnt about the mechanics of macropinosome formation.

\section{THE FUNCTION OF CONSTITUTIVE MACROPINOCYTOSIS: THE EVIDENCE FOR ANTIGEN PRESENTATION}

Growth factor induced macropinocytosis has a well-established role in the acquisition of extracellular solutes/nutrients in support of cell growth and metabolism (13). The functions of constitutive macropinocytosis on the other hand are significantly less clear. Given its relative specificity to macrophages and more notably immature dendritic cells, a role in the acquisition of antigen for subsequent processing and presentation to 
the adaptive arm of the immune system has been proposed (Figure 1) (7, 25-31). The notion that the primary function of constitutive macropinocytosis is to serve as a major route for the internalization of exogenous antigen however stands on strikingly shaky ground and deserves further consideration.

Antigen-presenting cells use a broad range of endocytic pathways for the internalization of exogenous antigen for processing and presentation (32). Therefore, linking constitutive macropinocytosis to antigen presentation requires methods for the specific manipulation of this mode of endocytosis. To date, an incomplete understanding of the mechanism of constitutive macropinocytosis along with its similarity to other modes of endocytosis, has left us with a dearth of techniques for the specific manipulation of macropinocytosis in vitro and even more so in vivo. Indeed, many of the pharmacological inhibitors of macropinocytosis are notoriously non-specific. For example, amiloride derivatives, one of the most frequently used inhibitors of macropinocytosis $(13,33-$ $35)$, are in fact promiscuous inhibitors of $\mathrm{Na}^{+} / \mathrm{H}^{+}$exchangers (36), $\mathrm{Na}^{+}$channels (37) and $\mathrm{Na}^{+} / \mathrm{Ca}^{2+}$ exchangers (38). The inhibitory effect of amiloride derivatives is a result of the dysregulation of submembranous $\mathrm{pH}$ due to impaired $\mathrm{Na}^{+} / \mathrm{H}^{+}$ exchange at sites of macropinocytosis (34). Importantly, this effect is neither specific to macropinocytosis nor to cell types capable of performing macropinocytosis. Yet, this inhibitor has been used to probe the effect of macropinocytosis on antigen presentation even in vivo (7) where it almost certainly has non-specific effects on a very wide range of cell types, including other immune cell types (39). Therefore, the effect of amiloride derivatives on macropinocytosis is incidental and cannot be used alone as a specific inhibitor of macropinocytosis. Moreover, their effect on antigen presentation in vivo need not be linked to macropinocytosis as $\mathrm{Na}^{+} / \mathrm{H}^{+}$exchangers have been linked to a wide range of immune cell functions including cell migration, apoptosis, differentiation, and even proliferation (40). It is also worth noting that, unlike growth factor induced macropinocytosis, the constitutive form of macropinocytosis is only marginally sensitive to amiloride derivatives (6). Other pharmacological agents including rottlerin $(30,41)$, rapamycin (25), and sanglifehrin A (26) have been used to study antigen uptake by macropinocytosis both in vitro and in vivo but are similarly non-specific and only limited conclusions can be drawn from such studies.

A more specific way to study macropinocytosis employs tagged fluid-phase tracers often in conjunction with pharmacological inhibition. An important consideration is the hydrodynamic radius of the fluid phase tracer, which must be sufficiently large so as to not be taken up via other modes of endocytosis. For example, soluble, fluorescently-tagged 70 $\mathrm{kDa}$ dextran is large enough to be selectively taken up by macropinocytosis, but not other smaller forms of endocytosis such as clathrin-mediated endocytosis or caveolae (42). Somewhat surprisingly, the majority of the studies linking macropinocytosis to antigen presentation have used either fluid-phase tracers that can be taken up by various forms of endocytosis or fluorescent dextran molecules of unknown size $(7,25,28,29,31,43,44)$. For example, fluorescently tagged ovalbumin is frequently used to study antigen uptake by macropinocytosis $(27,31,43)$, yet it is known that ovalbumin uptake by myeloid cells occurs predominantly via the mannose receptor in clathrin-coated pits $(45,46)$.

Clearly, the contribution of constitutive macropinocytosis to the uptake of antigen and its subsequent presentation could benefit from a more detailed understanding of its mechanism and therefore a more targeted assessment of tis role. Recent findings are bringing us closer to that goal. A selective agonist of the CaSR, NPS2143, inhibits constitutive macropinocytosis in primary human macrophages and dendritic cells without affecting clathrin-dependent endocytosis, growth factor induced macropinocytosis or phagocytosis $(6,9)$. NPS2143 represents a potentially powerful tool for assessing antigen uptake via macropinocytosis in vitro; however, its use in vivo is limited due to expression of CaSR by other cell types. Nevertheless, the myeloid-specific deletion of CaSR in vivo could bring us closer to understanding the role of constitutive macropinocytosis in antigen presentation.

\section{ARE THERE OTHER FUNCTIONS FOR CONSTITUTIVE MACROPINOCYTOSIS?}

Given the enormous volume of extracellular fluid that primary macrophages and dendritic cells turn over via constitutive macropinocytosis, it is likely that antigen, as discussed above, can enter for subsequent processing and presentation (Figure 1). Bulk extracellular fluid uptake however is not a particularly efficient means of internalizing antigen. Indeed, mathematical modeling has shown that receptor-dependent uptake, as opposed to fluid phase bulk uptake, requires 1,000-fold less antigen for efficient internalization and subsequent presentation (47). Moreover, receptor-dependent uptake provides a certain degree of selectivity for self vs. non-self cargo and allows for the sorting of antigen to an intracellular compartment that is competent for antigen presentation $(32,48)$. It is entirely unclear whether mechanisms for the concentration of antigen exist or if the differential sorting of macropinocytic cargo occurs after macropinosome formation. In addition, the observation that other antigen presenting cells like B cells, mature dendritic cells and inflammatory macrophages, all of which do not perform macropinocytosis $(44,49)$, are still capable of internalizing and presenting antigen $(32,50,51)$ begs the question of whether constitutive macropinocytosis may serve other functions.

We have recently proposed a novel surveillance function for constitutive macropinocytosis in macrophages and immature dendritic cells. Both macrophages and dendritic cells express a broad array of pattern recognition receptors (PRRs) for the detection of non-self and/or altered-self material in the extracellular milieu. PRRs are essential to the sentinel function of myeloid cells in that they allow them to respond to potential pathogens or damaged cells through the detection of MAMPs or damage associated molecular patterns (DAMPs), respectively. Myeloid cells respond by initiating gene transcription and translation pathways that result in both metastable changes to myeloid cell function and the production of soluble signals that 
can propagate responses to neighboring cells [reviewed in (5256)]. Although many PRRs are located on the exofacial leaflet of the plasma membrane, others are located in intracellular compartments (Figure 1) (57). Ligands for intracellular PRRs can be delivered via receptor-mediated endocytosis and phagocytosis [reviewed in (58)]. However, under circumstances where neither receptor-mediated endocytosis nor phagocytosis apply, macropincytosis serves as an ideal means for delivering ligands to intracellular PRRs. This is most convincingly revealed through the study of outer membrane vesicles (OMVs) that are shed by microbes during infection. OMVs, which can have a diameter larger than $300 \mathrm{~nm}$ (59), are shed by Gram-negative bacteria and have been implicated in the establishment of a replicative niche by pathogenic species (60). Importantly, OMVs can travel to sites that are distant from the initial site of infection and activate intracellular PRRs such as NOD1 (61-64). Interestingly, biophysical studies of receptor-mediated endocytosis have determined that the size optimum for the uptake of spherical particles is around $25-30 \mathrm{~nm}$, placing the large majority of OMVs squarely outside the optimal range for uptake via mechanisms such as clathrin-mediated endocytosis (65-68). Likewise, the size optimum for the uptake of particles by phagocytosis is between 2 and $3 \mu \mathrm{m}$ with efficiency decreasing dramatically when particles are below $1 \mu \mathrm{m}$, rendering phagocytosis of OMVs unlikely (69). Macropinosomes vary dramatically in size and can be anywhere from $250 \mathrm{~nm}$ to $5 \mu \mathrm{m}$ in size, which is favorable for the uptake of OMVs $(3,4)$. It is conceivable then that macropinocytosis can facilitate the capture of OMVs and the delivery of intracellular PRR ligands present on or within OMVs to their respective receptors. In line with this, we have shown that macropinosomes are competent in the delivery of the PRR NOD1/2 ligands to the cytosol for sensing (6), most likely via $\mathrm{pH}$-dependent solute carriers present on the membrane of the macropinosomes (Figure 1) (70-72). The contribution of constitutive macropinocytosis to the delivery of ligand to intracellular PRRs is sufficiently large that acutely turning off constitutive macropinocytosis completely ablates NOD1 signaling in macrophages (6).

The above observations notwithstanding, very few studies have begun to explore the uptake of OMVs, let alone other material shed and/or secreted by potential pathogens, by constitutive macropinocytosis (73, 74). After sealing, macropinosomes quickly acidify (75). Acidification is largely due to the delivery and accumulation of the vacuolar $\mathrm{H}^{+}$-ATPase $(\mathrm{V}$ ATPase) on the macropinsomal membrane through membrane fusion and fission events with components of the late endocytic and lysosomal compartments (76). The rate of acidification is also likely to be influenced by several additional factors including the buffering power of the luminal contents, the rate of proton leakage, consumption of protons by reactive oxygen species (ROS) generated by the NADPH oxidase (Figure 1), and the permeability of the macropinosomal membrane to counterions (77-79). Luminal acidification activates various hydrolases, lipases, and proteases with acidic $\mathrm{pH}$ optima (5). The degradative environment serves as an ideal compartment for the unmasking and ultimate $\mathrm{pH}$-dependent delivery of PRR ligands to the cytosol. Similarly, several transmembrane PRRs either require an acidic compartment for optimal binding to their ligands, as is the case for TLR3 (80), change their downstream signaling once internalized, as is the case for TLR4 (81), or are predominantly located in an endolysosomal compartment, as is the case for TLR7 and TLR9 (Figure 1) (82). Indeed, new studies are beginning to show that macropinosomes do serve as specialized signaling platforms for various intracellular TLRs (83).

A clear role for macropinocytosis in immune surveillance, not just antigen presentation, begins to emerge. Of interest is the tunability of constitutive macropinocytosis by myeloid cells. Homeostatic macrophages and anti-inflammatory macrophages, for example, perform constitutive macropinocytosis. Inflammatory macrophages do not undergo constitutive macropinocytosis (9). As such, macrophages can control under what conditions PRR ligands are delivered to their intracellular receptors, and whether certain PRRs encounter ligand at the plasma membrane or in an intracellular compartment. This becomes particularly relevant at sites of continuous contact with non-self material such as in the lung or gut. Interestingly, OMVs produced by microbes in the gut are internalized by gut-resident macrophages and dendritic cells and have an immunomodulatory effect $(84,85)$. Dendritic cells can also control their macropinocytic activity as they diminish their capacity for macropinocytosis upon maturation $(44,49,86)$. Although this may largely represent a shift from antigen capture to the maintenance of MHC complexes on a quiescent plasma membrane, it too may impact the signaling capacity of PRRs both in intracellular compartments and at the plasma membrane. Intriguingly, through unclear mechanisms, extracellular calcium is elevated at sites of tissue injury and infection $(87,88)$ and myeloid cells have been shown to sense these changes via the CaSR (88). Given the dose-dependent nature of calciumdependent constitutive macropinocytosis (6), local increases in extracellular calcium at sites of tissue injury and infection also represent an opportunity for enhancing macropinocytic activity and therefore the delivery of PRRs to intracellular compartments. Constitutive macropinocytosis then represents not only a means for antigen capture, but a tunable and efficient mechanism for the delivery of ligand to PRRs.

\section{CONCLUSION}

Innate immune cells are considered sentinels, uniquely endowed with an armory of PRRs that allow them to sense and distinguish between self, altered self, commensal non-self and pathogenic non-self material. The mechanics of sensing through PRRs is far more nuanced than previously appreciated and it is increasingly acknowledged that the subcellular compartmentalization of signaling platforms results in distinct responses. The enormous energy cost incurred by macrophages and dendritic cells in the performance of constitutive macropinocytosis was previously explained as a means of improving antigen capture. Indeed antigen can be captured by bulk fluid uptake although, as discussed above, it is not a particularly efficient means of doing so. A new function for constitutive macropinocytosis 
is emerging in the delivery of ligands to their respective intracellular PRRs. As such, constitutive macropinocytosis, which is unique to dendritic cells and macrophages, facilitates a defining feature of this subset of cells-immune surveillance. A closer look at how macropinosomes serve as signaling platforms and how they facilitate the delivery of ligands to both membrane bound and cytosolic PRRs is warranted. An improved knowledge of constitutive macropinocytosisis is therefore essential as it has clear implications in the regulation of immunity.

\section{REFERENCES}

1. Tauber AI. Metchnikoff and the phagocytosis theory. Nat Rev Mol Cell Biol. (2003) 4:897-901. doi: 10.1038/nrm1244

2. Schmid SL, Sorkin A, Zerial M. Endocytosis: past, present, and future. Cold Spring Harb Perspect Biol. (2014) 6:a022509. doi: 10.1101/cshperspect.a022509

3. Swanson JA, Watts C. Macropinocytosis. Trends Cell Biol. (1995) 5:424-8. doi: 10.1016/S0962-8924(00)89101-1

4. Lim JP, Gleeson PA. Macropinocytosis: an endocytic pathway for internalising large gulps. Immunol Cell Biol. (2011) 89:836-43. doi: 10.1038/icb.2011.20

5. Marques PE, Grinstein S, Freeman SA. SnapShot:Macropinocytosis. Cell (2017) 169:766-766.e1. doi: 10.1016/j.cell.2017.04.031

6. Canton J, Schlam D, Breuer C, Gütschow M, Glogauer M, Grinstein S. Calcium-sensing receptors signal constitutive macropinocytosis and facilitate the uptake of NOD2 ligands in macrophages. Nat Commun. (2016) 7:11284. doi: $10.1038 /$ ncomms 11284

7. Delwig A von, Hilkens CMU, Altmann DM, Holmdahl R, Isaacs JD, Harding $\mathrm{CV}$, et al. Inhibition of macropinocytosis blocks antigen presentation of type II collagen in vitro and in vivo in HLA-DR1 transgenic mice. Arthritis Res Ther. (2006) 8:R93. doi: 10.1186/ar1964

8. West MA, Wallin RPA, Matthews SP, Svensson HG, Zaru R, Ljunggren HG, et al. Enhanced dendritic cell antigen capture via toll-like receptor-induced actin remodeling. Science (2004) 305:1153-57. doi: 10.1126/science.1099153

9. Redka DS, Gütschow M, Grinstein S, Canton J. Differential ability of proinflammatory and anti-inflammatory macrophages to perform macropinocytosis. Mol Biol Cell (2018) 29:53-65. doi: 10.1091/mbc.E17-06-0419

10. Steinman RM, Brodie SE, Cohn ZA. Membrane flow during pinocytosis. A stereologic analysis. J Cell Biol. (1976) 68:665-87.

11. Flannagan RS, Harrison RE, Yip CM, Jaqaman K, Grinstein S. Dynamic macrophage "probing" is required for the efficient capture of phagocytic targets. J Cell Biol. (2010) 191:1205-18. doi: 10.1083/jcb.201007056

12. Welliver TP, Swanson JA. A growth factor signaling cascade confined to circular ruffles in macrophages. Biol Open (2012) 1:754-60. doi: 10.1242/bio.20121784

13. Yoshida S, Pacitto R, Inoki K, Swanson J. Macropinocytosis, mTORC1 and cellular growth control. Cell Mol Life Sci. (2018) 75:1227-39. doi: 10.1007/s00018-017-2710-y

14. Amyere M, Payrastre B, Krause U, Van Der Smissen P, Veithen A, Courtoy PJ. Constitutive macropinocytosis in oncogene-transformed fibroblasts depends on sequential permanent activation of phosphoinositide 3-kinase and phospholipase C. Mol Biol Cell (2000) 11:3453-67. doi: $10.1091 / \mathrm{mbc} .11 .10 .3453$

15. Bohdanowicz M, Schlam D, Hermansson M, Rizzuti D, Fairn GD, Ueyama $\mathrm{T}$, et al. Phosphatidic acid is required for the constitutive ruffling and macropinocytosis of phagocytes. Mol Biol Cell (2013) 24:1700-12, S1-7. doi: 10.1091/mbc.E12-11-0789

16. Sanematsu F, Nishikimi A, Watanabe M, Hongu T, Tanaka Y, Kanaho Y, et al. Phosphatidic acid-dependent recruitment and function of the Rac activator DOCK1 during dorsal ruffle formation. J Biol Chem. (2013) 288:8092-100. doi: 10.1074/jbc.M112.410423

17. Campellone KG, Welch MD. A nucleator arms race: cellular control of actin assembly. Nat Rev Mol Cell Biol. (2010) 11:237-51. doi: 10.1038/nr $\mathrm{m} 2867$

\section{AUTHOR CONTRIBUTIONS}

The author confirms being the sole contributor of this work and has approved it for publication.

\section{ACKNOWLEDGMENTS}

I would like to thank the reviewers for their scientific input and critical reading of this manuscript.

18. Cox D, Chang P, Zhang Q, Reddy PG, Bokoch GM, Greenberg S. Requirements for both Racl and Cdc42 in membrane ruffling and phagocytosis in leukocytes. J Exp Med. (1997) 186:1487-94. doi: $10.1084 /$ jem.186.9.1487

19. Oikawa T, Yamaguchi H, Itoh $\mathrm{T}$, Kato $\mathrm{M}$, Ijuin $\mathrm{T}$, Yamazaki D, et al. PtdIns(3,4,5)P3 binding is necessary for WAVE2-induced formation of lamellipodia. Nat Cell Biol. (2004) 6:420-6. doi: 10.1038/ncb1125

20. Jenkins GH, Fisette PL, Anderson RA. Type I phosphatidylinositol 4phosphate 5-kinase isoforms are specifically stimulated by phosphatidic acid. J Biol Chem. (1994) 269:11547-54.

21. Roach AN, Wang Z, Wu P, Zhang F, Chan RB, Yonekubo Y, et al. Phosphatidic acid regulation of PIPKI is critical for actin cytoskeletal reorganization. J Lipid Res. (2012) 53:2598-609. doi: 10.1194/jlr.M028597

22. Maekawa M, Terasaka S, Mochizuki Y, Kawai K, Ikeda Y, Araki N, et al. Sequential breakdown of 3-phosphorylated phosphoinositides is essential for the completion of macropinocytosis. Proc Natl Acad Sci USA. (2014) 111:E978-87. doi: 10.1073/pnas.1311029111

23. Yoshida S, Hoppe AD, Araki N, Swanson JA. Sequential signaling in plasmamembrane domains during macropinosome formation in macrophages. J Cell Sci. (2009) 122:3250-61. doi: 10.1242/jcs.053207

24. Veltman DM, Williams TD, Bloomfield G, Chen BC, Betzig E, Insall RH, et al. A plasma membrane template for macropinocytic cups. eLife (2016) 5:e20085. doi: 10.7554/eLife.20085

25. Hackstein H, Taner T, Logar AJ, Thomson AW. Rapamycin inhibits macropinocytosis and mannose receptor-mediated endocytosis by bone marrow-derived dendritic cells. Blood (2002) 100:1084-7. doi: 10.1182/blood.V100.3.1084

26. Hackstein H, Steinschulte C, Fiedel S, Eisele A, Rathke V, Stadlbauer T, et al. Sanglifehrin a blocks key dendritic cell functions in vivo and promotes longterm allograft survival together with low-dose CsA. Am J Transplant. (2007) 7:789-98. doi: 10.1111/j.1600-6143.2006.01729.x

27. Lim JP, Teasdale RD, Gleeson PA. SNX5 is essential for efficient macropinocytosis and antigen processing in primary macrophages. Biol Open (2012) 1:904-14. doi: 10.1242/bio.20122204

28. Norbury CC, Chambers BJ, Prescott AR, Ljunggren HG, Watts C. Constitutive macropinocytosis allows TAP-dependent major histocompatibility complex class I presentation of exogenous soluble antigen by bone marrow-derived dendritic cells. Eur J Immunol. (1997) 27:280-8. doi: 10.1002/eji.1830270141

29. Sallusto F, Cella M, Danieli C, Lanzavecchia A. Dendritic cells use macropinocytosis and the mannose receptor to concentrate macromolecules in the major histocompatibility complex class II compartment: downregulation by cytokines and bacterial products. J Exp Med. (1995) 182:389-400. doi: 10.1084/jem.182.2.389

30. Sarkar K, Kruhlak MJ, Erlandsen SL, Shaw S. Selective inhibition by rottlerin of macropinocytosis in monocyte-derived dendritic cells. Immunology (2005) 116:513-24. doi: 10.1111/j.1365-2567.2005.02253.x

31. Singla B, Ghoshal P, Lin H, Wei Q, Dong Z, Csányi G. PKC $\delta$-mediated Nox2 activation promotes fluid-phase pinocytosis of antigens by immature dendritic cells. Front Immunol. (2018) 9:537. doi: 10.3389/fimmu.2018.00537

32. Blum JS, Wearsch PA, Cresswell P. Pathways of antigen processing. Annu Rev Immunol. (2013) 31:443-73. doi: 10.1146/annurev-immunol-032712-095910

33. Ford C, Nans A, Boucrot E, Hayward RD. Chlamydia exploits filopodial capture and a macropinocytosis-like pathway for host cell entry. PLoS Pathog. (2018) 14:e1007051. doi: 10.1371/journal.ppat.1007051 
34. Koivusalo M, Welch C, Hayashi H, Scott CC, Kim M, Alexander T, et al. Amiloride inhibits macropinocytosis by lowering submembranous $\mathrm{pH}$ and preventing Racl and Cdc42 signaling. J Cell Biol. (2010) 188:547-63. doi: $10.1083 /$ jcb.200908086

35. Levican J, Miranda-Cárdenas C, Soto-Rifo R, Aguayo F, Gaggero A, León O. Infectious pancreatic necrosis virus enters CHSE-214 cells via macropinocytosis. Sci Rep. (2017) 7:3068. doi: 10.1038/s41598-017-03036-w

36. Orlowski J, Grinstein S. Na+/H+ exchangers. Compr Physiol. (2011) 1:2083100. doi: 10.1002/cphy.c110020

37. Alvarez de la Rosa D, Canessa CM, Fyfe GK, Zhang P. Structure and regulation of amiloride-sensitive sodium channels. Annu Rev Physiol. (2000) 62:573-94. doi: 10.1146/annurev.physiol.62.1.573

38. Masereel B, Pochet L, Laeckmann D. An overview of inhibitors of $\mathrm{Na}(+) / \mathrm{H}(+)$ exchanger. Eur J Med Chem. (2003) 38:547-54. doi: 10.1016/S0223-5234(03)00100-4

39. Shi Y, Kim D, Caldwell M, Sun D. The role of $\mathrm{Na}(+) / \mathrm{h}(+)$ exchanger isoform 1 in inflammatory responses: maintaining $\mathrm{H}(+)$ homeostasis of immune cells. Adv Exp Med Biol. (2013) 961:411-8. doi: 10.1007/978-1-4614-4756-6_35

40. De Vito P. The sodium/hydrogen exchanger: a possible mediator of immunity. Cell Immunol. (2006) 240:69-85. doi: 10.1016/j.cellimm.2006.07.001

41. Ménager MM, Littman DR. Actin dynamics regulates dendritic cellmediated transfer of HIV-1 to T Cells. Cell (2016) 164:695-709. doi: 10.1016/j.cell.2015.12.036

42. Li L, Wan T, Wan M, Liu B, Cheng R, Zhang R. The effect of the size of fluorescent dextran on its endocytic pathway. Cell Biol Int. (2015) 39:531-9. doi: 10.1002/cbin.10424

43. Norbury CC, Hewlett LJ, Prescott AR, Shastri N, Watts C. Class I MHC presentation of exogenous soluble antigen via macropinocytosis in bone marrow macrophages. Immunity (1995) 3:783-91. doi: 10.1016/1074-7613(95)90067-5

44. West MA, Prescott AR, Eskelinen EL, Ridley AJ, Watts C. Rac is required for constitutive macropinocytosis by dendritic cells but does not control its downregulation. Curr Biol. (2000) 10:839-48. doi: 10.1016/S0960-9822(00)00595-9

45. Autenrieth SE, Autenrieth IB. Variable antigen uptake due to different expression of the macrophage mannose receptor by dendritic cells in various inbred mouse strains. Immunology (2009) 127:523-9. doi: 10.1111/j.1365-2567.2008.02960.x

46. Burgdorf S, Lukacs-Kornek V, Kurts C. The mannose receptor mediates uptake of soluble but not of cell-associated antigen for cross-presentation. $J$ Immunol. (2006) 176:6770-6. doi: 10.4049/jimmunol.176.11.6770

47. Singer DF, Linderman JJ. The relationship between antigen concentration, antigen internalization, and antigenic complexes: modeling insights into antigen processing and presentation. J Cell Biol. (1990) 111:55-68. doi: $10.1083 /$ jcb.111.1.55

48. Burgdorf S, Kurts C. Endocytosis mechanisms and the cell biology of antigen presentation. Curr Opin Immunol. (2008) 20:89-95. doi: 10.1016/j.coi.2007.12.002

49. Garrett WS, Chen LM, Kroschewski R, Ebersold M, Turley S, Trombetta S, Galán JE, Mellman I. Developmental control of endocytosis in dendritic cells by Cdc42. Cell (2000) 102:325-34. doi: 10.1016/S0092-8674(00)00038-6

50. Platt CD, Ma JK, Chalouni C, Ebersold M, Bou-Reslan H, Carano RAD, et al. Mature dendritic cells use endocytic receptors to capture and present antigens. Proc Natl Acad Sci USA. (2010) 107:4287-92. doi: 10.1073/pnas.0910609107

51. Arnold CE, Gordon P, Barker RN, Wilson HM. The activation status of human macrophages presenting antigen determines the efficiency of Th17 responses. Immunobiology (2015) 220:10-19. doi: 10.1016/j.imbio.2014.09.022

52. Amit I, Winter DR, Jung S. The role of the local environment and epigenetics in shaping macrophage identity and their effect on tissue homeostasis. Nat Immunol. (2016) 17:18-25. doi: 10.1038/ni.3325

53. Varol C, Mildner A, Jung S. Macrophages: development and tissue specialization. Annu Rev Immunol. (2015) 33:643-75. doi: 10.1146/annurev-immunol-032414-112220

54. Mills CD. Anatomy of a discovery: $\mathrm{m} 1$ and $\mathrm{m} 2$ macrophages. Front Immunol. (2015) 6:212. doi: 10.3389/fimmu.2015.00212

55. Wynn TA, Chawla A, Pollard JW. Macrophage biology in development, homeostasis and disease. Nature (2013) 496:445-55. doi: 10.1038/nature12034
56. Paul F, Amit I. Plasticity in the transcriptional and epigenetic circuits regulating dendritic cell lineage specification and function. Curr Opin Immunol. (2014) 30:1-8. doi: 10.1016/j.coi.2014.04.004

57. Brubaker SW, Bonham KS, Zanoni I, Kagan JC. Innate immune pattern recognition: a cell biological perspective. Annu Rev Immunol. (2015) 33:25790. doi: 10.1146/annurev-immunol-032414-112240

58. Motta V, Soares F, Sun T, Philpott DJ. NOD-like receptors: versatile cytosolic sentinels. Physiol Rev. (2015) 95:149-78. doi: 10.1152/physrev.00009.2014

59. Roier S, Zingl FG, Cakar F, Durakovic S, Kohl P, Eichmann TO, et al. A novel mechanism for the biogenesis of outer membrane vesicles in Gram-negative bacteria. Nat Commun. (2016) 7:10515. doi: 10.1038/ncomms10515

60. Jan AT. Outer Membrane Vesicles (OMVs) of gram-negative bacteria: a perspective update. Front Microbiol. (2017) 8:1053. doi: $10.3389 /$ fmicb.2017.01053

61. Guidi R, Levi L, Rouf SF, Puiac S, Rhen M, Frisan T. Salmonella enterica delivers its genotoxin through outer membrane vesicles secreted from infected cells. Cell Microbiol. (2013) 15:2034-50. doi: 10.1111/cmi.12172

62. Bielig H, Rompikuntal PK, Dongre M, Zurek B, Lindmark B, Ramstedt M, et al. NOD-like receptor activation by outer membrane vesicles from Vibrio cholerae Non-O1 non-O139 strains is modulated by the quorum-sensing regulator HapR. Infect Immun. (2011) 79:1418-27. doi: 10.1128/IAI.00754-10

63. Cañas MA, Fábrega MJ, Giménez R, Badia J, Baldomà L. Outer membrane vesicles from probiotic and commensal Escherichia coli activate NOD1mediated immune responses in intestinal epithelial cells. Front Microbiol. (2018) 9:498. doi: 10.3389/fmicb.2018.00498

64. Vanaja SK, Russo AJ, Behl B, Banerjee I, Yankova M, Deshmukh SD, et al. Bacterial outer membrane vesicles mediate cytosolic localization of LPS and caspase-11 activation. Cell (2016) 165:1106-19. doi: 10.1016/j.cell.2016.04.015

65. Gao H, Shi W, Freund LB. Mechanics of receptor-mediated endocytosis. Proc Natl Acad Sci USA. (2005) 102:9469-74. doi: 10.1073/pnas.0503879102

66. Aoyama Y, Kanamori T, Nakai T, Sasaki T, Horiuchi S, Sando S, et al. Artificial viruses and their application to gene delivery. Size-controlled gene coating with glycocluster nanoparticles. J Am Chem Soc. (2003) 125:3455-7. doi: $10.1021 /$ ja029608t

67. Nakai T, Kanamori T, Sando S, Aoyama Y. Remarkably size-regulated cell invasion by artificial viruses. Saccharide-dependent self-aggregation of glycoviruses and its consequences in glycoviral gene delivery. J Am Chem Soc. (2003) 125:8465-75. doi: 10.1021/ja035636f

68. Osaki F, Kanamori T, Sando S, Sera T, Aoyama Y. A quantum dot conjugated sugar ball and its cellular uptake. On the size effects of endocytosis in the subviral region. J Am Chem Soc. (2004) 126:6520-1. doi: 10.1021/ja048792a

69. Champion JA, Walker A, Mitragotri S. Role of particle size in phagocytosis of polymeric microspheres. Pharm Res. (2008) 25:1815-21. doi: $10.1007 /$ s11095-008-9562-y

70. Lee J, Tattoli I, Wojtal KA, Vavricka SR, Philpott DJ, Girardin SE. pHdependent internalization of muramyl peptides from early endosomes enables Nod1 and Nod2 signaling. J Biol Chem. (2009) 284:23818-29. doi: 10.1074/jbc.M109.033670

71. Irving AT, Mimuro H, Kufer TA, Lo C, Wheeler R, Turner LJ, et al. The immune receptor NOD1 and kinase RIP2 interact with bacterial peptidoglycan on early endosomes to promote autophagy and inflammatory signaling. Cell Host Microbe. (2014) 15:623-35. doi: 10.1016/j.chom.2014.04.001

72. Nakamura N, Lill JR, Phung Q, Jiang Z, Bakalarski C, de Mazière A, et al. Endosomes are specialized platforms for bacterial sensing and NOD2 signalling. Nature (2014) 509:240-4. doi: 10.1038/nature13133

73. O'Donoghue EJ, Krachler AM. Mechanisms of outer membrane vesicle entry into host cells. Cell Microbiol. (2016) 18:1508-17. doi: 10.1111/cmi.12655

74. Bomberger JM, Maceachran DP, Coutermarsh BA, Ye S, O’Toole GA, Stanton BA. Long-distance delivery of bacterial virulence factors by Pseudomonas aeruginosa outer membrane vesicles. PLoS Pathog. (2009) 5:e1000382. doi: 10.1371/journal.ppat.1000382

75. Racoosin EL, Swanson JA. Macropinosome maturation and fusion with tubular lysosomes in macrophages. J Cell Biol. (1993) 121:1011-20. doi: $10.1083 /$ jcb.121.5.1011

76. Buckley CM, Gopaldass N, Bosmani C, Johnston SA, Soldati T, Insall RH, King JS. WASH drives early recycling from macropinosomes and phagosomes 
to maintain surface phagocytic receptors. Proc Natl Acad Sci USA. (2016) 113:E5906-15. doi: 10.1073/pnas.1524532113

77. Canton J, Khezri R, Glogauer M, Grinstein S. Contrasting phagosome pH regulation and maturation in human M1 and M2 macrophages. Mol Biol Cell (2014) 25:3330-41. doi: 10.1091/mbc.e14-05-0967

78. Jankowski A, Scott CC, Grinstein S. Determinants of the phagosomal pH in neutrophils. J Biol Chem. (2002) 277:6059-66. doi: 10.1074/jbc.M1100 59200

79. Canton J. Phagosome maturation in polarized macrophages. J Leukoc Biol. (2014) 96:729-38. doi: 10.1189/jlb.1MR0114-021R

80. Leonard JN, Ghirlando R, Askins J, Bell JK, Margulies DH, Davies DR, et al. The TLR3 signaling complex forms by cooperative receptor dimerization. Proc Natl Acad Sci USA. (2008) 105:258-63. doi: 10.1073/pnas.07107 79105

81. Tan Y, Zanoni I, Cullen TW, Goodman AL, Kagan JC. Mechanisms of Toll-like receptor 4 endocytosis reveal a common immune-evasion strategy used by pathogenic and commensal bacteria. Immunity (2015) 43:909-22. doi: 10.1016/j.immuni.2015.10.008

82. Chaturvedi A, Pierce SK. How location governs Toll like receptor signaling. Traffic (2009) 10:621-8. doi: 10.1111/j.1600-0854.2009.00899.x

83. Wall AA, Luo L, Hung Y, Tong SJ, Condon ND, Blumenthal A, et al. Small GTPase Rab8a-recruited phosphatidylinositol 3-kinase $\gamma$ regulates signaling and cytokine outputs from endosomal toll-like receptors. J Biol Chem. (2017) 292:4411-22. doi: 10.1074/jbc.M116.766337

84. Shen Y, Torchia MLG, Lawson GW, Karp CL, Ashwell JD, Mazmanian SK. Outer membrane vesicles of a human commensal mediate immune regulation and disease protection. Cell Host Microbe (2012) 12:509-20. doi: 10.1016/j.chom.2012.08.004
85. Hickey CA, Kuhn KA, Donermeyer DL, Porter NT, Jin C, Cameron EA, et al. Colitogenic bacteroides thetaiotaomicron antigens access host immune cells in a sulfatase-dependent manner via outer membrane vesicles. Cell Host Microbe (2015) 17:672-80. doi: 10.1016/j.chom.2015.04.002

86. Calmette J, Bertrand $M$, Vétillard $M$, Ellouze $M$, Flint $S$, Nicolas $\mathrm{V}$, et al. Glucocorticoid-induced leucine zipper protein controls macropinocytosis in dendritic cells. J Immunol. (2016) 197:4247-56. doi: 10.4049/jimmunol.1600561

87. Lin CY, Huang TP. Enhancement of ionized calcium and 1,25dihydroxycholecalciferol loss from peritoneal fluid during peritonitis in patients treated with continuous ambulatory peritoneal dialysis. Nephron (1991) 59:90-5. doi: 10.1159/000186525

88. Olszak IT, Poznansky MC, Evans RH, Olson D, Kos C, Pollak MR, et al. Extracellular calcium elicits a chemokinetic response from monocytes in vitro and in vivo. J Clin Invest. (2000) 105:1299-305. doi: 10.1172/JCI9799

Conflict of Interest Statement: The author declares that the research was conducted in the absence of any commercial or financial relationships that could be construed as a potential conflict of interest.

The reviewer GS and handling Editor declared their shared affiliation.

Copyright (C) 2018 Canton. This is an open-access article distributed under the terms of the Creative Commons Attribution License (CC BY). The use, distribution or reproduction in other forums is permitted, provided the original author $(s)$ and the copyright owner(s) are credited and that the original publication in this journal is cited, in accordance with accepted academic practice. No use, distribution or reproduction is permitted which does not comply with these terms. 